\title{
Potensi Pemanfaatan Teripang (Holothurians) di Perairan Karimunjawa, Kabupaten Jepara, Provinsi Jawa
}

\author{
Bambang Sulardiono \\ Program Studi Manajemen Sumberdaya Perairan \\ Jurusan Perikanan Fakultas Perikanan dan Ilmu Kelautan Universitas Diponegoro \\ Email: bambang_sular@yahoo.co.id
}

\begin{abstract}
Abstrak
Terdapat beragam spesies teripang (Holothurians) yang hidup di Perairan Karimunjawa, yang menempati berbagai substrat dasar pada ekosistem terumbu karang. Teripang bernilai ekonomis. Penangkapan dilakukan secara terus menerus tanpa adanya pengawasan. Hal inilah yang menyebabkan jumlah populasi teripang $H$. scabra menurun dengan tajam. Oleh sebab itu perlu diadakan penelitian untuk mengetahui kondisi potensi teripang (holothurians) tersebut. Tujuan penelitian adalah mengetahui (a) komposisi spesies teripang di perairan Karimunjawa (b) potensi populasi teripang di perairan Karimunjawa, dan (c) potensi pemanfatan teripang di perairan Karimunjawa.

Metode pengumpulan data menggunakan transek garis $100 \mathrm{~m}$ yang dimodifikasi untuk reef check. Pengukuran dilakukan selama 1 tahun dengan interval waktu 1 bulan. Lokasi penelitian di perairan Karimunjawa, dibagi dalam 5 titik sampling yaitu stasiun A Menjangan Kecil, Stasiun B Legon Goprak, Stasiun C Karang Gumuk, Stasiun D Alang-alang, dan Stasiun E Mrican.

Hasil penelitian menunjukkan bahwa terdapat 15 spesies teripang yang termasuk dalam ordo Aspidochirotidae dan 2 famili yaitu 11 spesies dari famili Holothuridae dan 4 spesies dari famili Stichopodidae. Potensi biomassa populasi seluruh spesies yang dimanfaatkan dalam area studi sampai pada kedalaman $10 \mathrm{~m}$, diketahui sebesar 44.641.789 individu dengan nilai potensi leatari (MSY) sebesar 24.590.814 individu per tahun, dengan kuota pengambilan yang diperbolehkan sebesar 20.277.981 individu per tahun. Potensi biomassa populasi spesies yang paling rendah adalah $H$. scabra, Actinopyga sp, dan A. lecanora masing-masing sebesar 756.594 individu, 756.458 individu, dan 1.134 .823 individu, dengan nilai potensi lestari (MSY) masing - masing untuk H. scabra sebesar 378.297 individu per tahun, Actinopyga sp sebesar 567.411 individu per tahun dan A. lecanora sebesar 378.229 individu per tahun, serta dengan kuota pengambilan masing-masing sebesar 302.637individu per tahun, 302.583 individu per tahun, dan 302.583 individu per tahun. Untuk dapat meningkatkan populasi Sumberdaya teripang (Holothurian) di perairan Karimunjawa secara lestari, maka strategi yang dilakukan adalah dengan mengembangkan sifat altruistik positip (responsible optimistic).
\end{abstract}

Kata kunci : teripang, potensi lestari, dan kuota tangkapan

\begin{abstract}
There are various species of sea cucumber (Holothurians) who live in the waters Karimunjawa, which occupy a variety of substrates on the basis of coral reef ecosystems. Catching sea cucumbers are performed continuously without any controls, so it tends to over-fishing. This is why the number of sea cucumber populations declined sharply. Therefore it is necessary to study to determine the condition of the potential of sea cucumbers (holothurians) is the research objective was to determine (a) the composition of species of sea cucumbers in the Karimunjawa waters, (b) the potential population of sea cucumbers in the Karimunjawa waters, and (c) the potential utilization of sea cucumbers in Karimunjawa waters.

Field data collection methods used $100 \mathrm{~m}$ line transect method modified for reef check. Preservation and identification of species found were then conducted. Field measurements carried out for 1 year at intervals of 1 month. Research sites in the waters Karimunjawa, divided into five sampling points are station A small deer, Legon Goprak Station B, Station C Reef dunes, Reed Station D, and E Mrican Station.
\end{abstract}


The results showed that there are 15 species of sea cucumbers belonging to the families and 2 orders Aspidochirotidae the 11 species of the family Holothuridae and 4 species of the family Stichopodidae. Both families have members of the species is commonly used and traded. There is information that the entire population of potential biomass species used in the study area to a depth of $10 \mathrm{~m}$, is found to be 44,641,789 individuals with the potential leatari (MSY) of 24,590,814 people per year, with the permitted quota of 20,277,981 individuals per year. Potential biomass low populations of most species is $H$. scabra, Actinopyga sp, and A. lecanora amounted to 756594 individuals, 756458 individuals, and 1,134,823 individuals, with the potential for sustainable (MSY) each - one for H. scabra of 378297 individuals per year, amounting to 567411 sp Actinopyga individuals per year and A. lecanora of 378229 individuals per year, and with their respective quota of 302637 individuals per year, 302583 individuals per year, and 302583 individuals per year. In order to increase the population of sea cucumber resources (Holothurian) in waters Karimunjawa sustainably, then the strategy taken is to develop the altruistic nature of the positive (Responsible optimistic).

Keywords: sea cucumber, sustainable potential, and fishing quota

\section{Pendahuluan}

Perairan Karimunjawa banyak didominasi oleh ekosistem terumbu karang dan padang lamun, walaupun keberadaan terumbu karang tidak mempengaruhi secara langsung keberadaan organismne teripang, oleh karena beragamnya substrat yang mendominasi, baik substrat dasar lunak maupun keras, memungkinkan untuk digunakannya substrat dasar perairan terumbu karang sebagai habitatnya. Teripang khususnya untuk teripang spesies tertentu diambil dan dimanfaatkan oleh nelayan setempat karena mempunyai nilai komersial yang sangat penting, dan harga yang relatif tinggi. Sebagai komoditas perdagangan, teripang banyak dibutuhkan, dan permintaan dari komoditas tersebut cenderung meningkat. Untuk mencukupi kebutuhan permintaan tersebut, nelayan menangkap teripang secara terus menerus tanpa adanya kontrol, sehingga cenderung over-eksploitasi, dan diduga menyebabkan terancamnya kelestaian populasi teripang tersebut. Mengingat pentingnya kelestarian populasi teripang di Perairan Karimunjawa, dan untuk dapat terjaminnya pemanfaatan kedepan, maka diperlukan data dan informasi tentang potensi populasi yang ada saat ini. Tujuan penelitian adalah mengetahui (a) komposisi spesies teripang di perairan Karimunjawa (b) potensi populasi teripang di perairan Karimunjawa, dan (c) potensi pemanfatan teripang di perairan Karimunjawa.

\section{Materi dan Metode \\ Lokasi Penelitian}

Lokasi penelitian di Perairan Karimunjawa, dibagi dalam 5 titik sampling yaitu stasiun A Menjangan Kecil, Stasiun B Legon Goprak, Stasiun C Karang Gumuk, Stasiun C Alang-alang, dan Stasiun E Mrican. Penelitian dilakukan selama 1 tahun dengan interval 1 bulan, sehingga diperoleh 6 kali pengambilan sampel, yaitu sejak bulan Juli 2009 hingga Mei 2010. Peta lokasi penelitian dapat dilihat pada Gambar 1 .

\section{Metode Pengumpulan data}

Metode yang digunakan adalah metode observasi dengan analisis diskriptif (Sandjaya, 2006), yaitu metode yang bersifat deskriptif untuk memperoleh fakta-fakta dari gejala-gejala yang ada dan mencari keterangan-keterangan secara faktual dari suatau kelompok ataupun suatu daerah kemudian dilakukan analisis lebih lanjut mengenai kebenaran tersebut. Metoda pengumpulan data dengan cara sistimatik sampling.

Sesuai dengan sifat hidup teripang yang fototaksis negatif, maka pengamatan dilakukan pada waktu malam hari pada tiap stasiun, mulai pukul 18.00 - 02.00 WIB.

Pengumpulan sampel teripang dilakukan dengan menggunakan metoda line transect dengan modifikasi Reef check untuk hewan megabenthos (Manuputty dan Djuwariah, 2009). Jika Manuputty dan Djuwariyah (2009) menggunakan panjang transek $25 \mathrm{~m}$, maka dalam penelitian ini menggunakan panjang transek $100 \mathrm{~m}$, dengan alasan digunakan untuk hewan megabenthos, seperti teripang. Selanjutnya dikatakan bahwa untuk sampling hewan mega benthos dapat digunakan panjang transek lebih dari $25 \mathrm{~m}$. Setiap lokasi stasiun penelitian diletakkan garis transek sepanjang $100 \mathrm{~m}$, Sampling teripang dilakukan dengan menggunakan kuadran ukuran 1 x $1 \mathrm{~m}$ yang diletakkan pada kanan dan kiri garis transek. Penempatan kuadran dimulai pada titik pertama garis transek hingga pada jarak 10m, dan seterusnya untuk titik kedua dengan jarak yang 
sama hingga sampling ke10, sehingga jarak antar kuadran yang pertama dengan kuadran yang kedua sama, yakni $9 \mathrm{~m}$ Jumlah transek pada setiap lokasi sebanyak 3 kali, Dengan demikian, total luas bidang lapang pandang kuadran untuk pengambilan teripang setiap transek adalah $3 \mathrm{x}$ $\left(2 \mathrm{~m}^{2} \mathrm{x} 10\right)=60 \mathrm{~m}^{2}$. Langkah selanjutnya adalah pengawetan sampel, dengan menggunakan formalin dan diamati lebih lanjut di laboratorium.

\section{Analisis data}

Analisis data yang digunakan meliputi (a) spesies dan jumlah individu spesies diketemukan di perairan Karimunjawa, (b) potensi sumberdaya teripang yang dimanfaatkan berdasarkan nilai densitas per, (c) potensi lestari dan potensi yang diperbolehkan ditangkap (kuota). Untuk menduga potensi lestari dan kuota pemanfaatan tersebut, digunakan data densitas individu per hektar dalam satu tahun efektif (dalam setahun diasumsikan dilakukan eksploitasi selama 9 bulan), sehingga dapat di estimasi potensi biomasa dari seluruh area studi sampai dengan kedalaman 10 meter. Tahapan analisis yang dilakukan meliputi:

a. Mengestimasi densitas individu per hektar

b. Mengestimasi nilai potensi biomass dalam area studies

c. Mengestimasi nilai potensi lestari maxsimum sustainebel yield (MSY) sebesar 0,5 x Biomass

d. Mengestimasi potensi kuota tangkapan yang diperbolehkan (JTB) yang mengacu pada Kepmentan No. 995/Kpts/IK.210/9/99 dan Kepmen KP No Kep. 18/Men/2002, yaitu sebesar $80 \%$ dari nilai MSY.

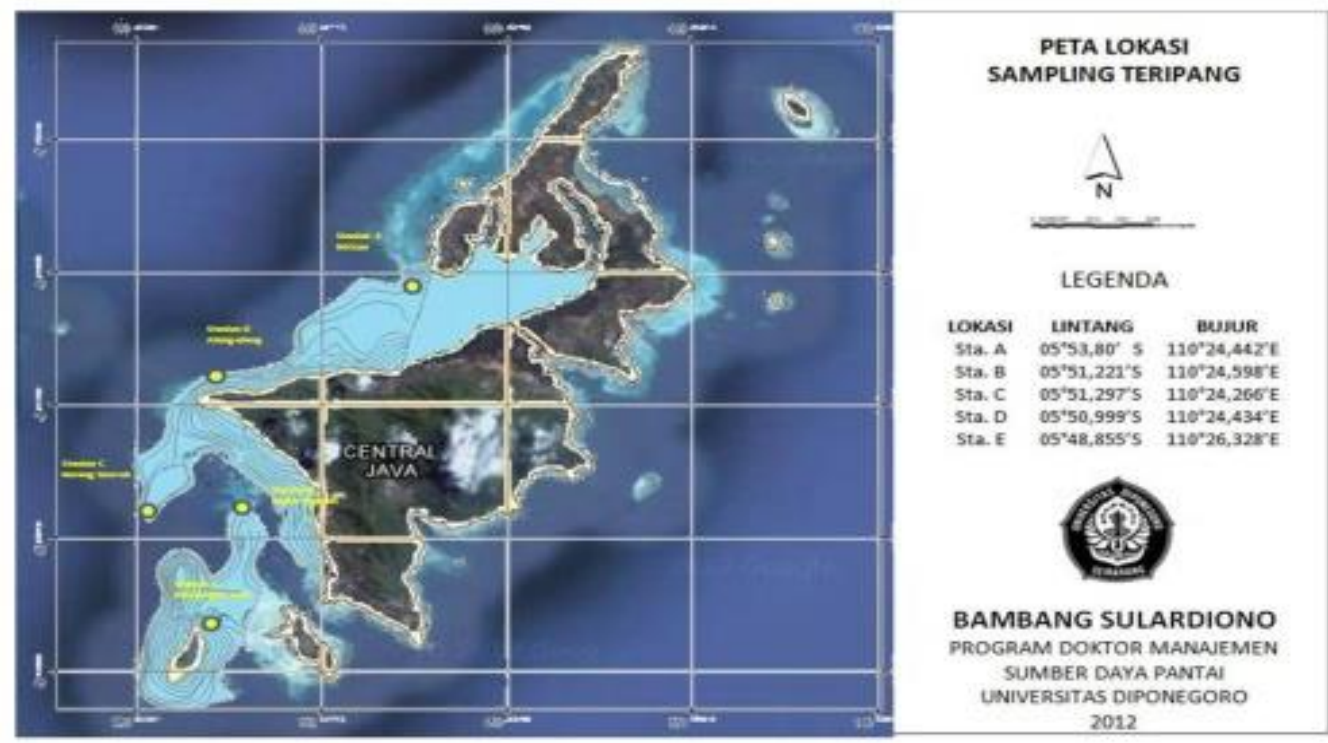

Gambar 1. Peta Lokasi Penelitian.

Sumber : Diolah dari Peta kedalaman Perairan Karimunjawa (Deshidros, TNI-AL, 2002).

Data densitas individu teripang per hektar secara time series selama 1 tahun dan luasan area studi sampai pada kedalaman 10m.Densitas Individu per Area dihitung berdasarkan rumus (Misra, 1968), yaitu :

Densitas $=\frac{\text { Jumlah individu spesies } k e-\mathbf{i}}{\text { Jumlah luas petakan dalam transek }}$

Keterangan :

Jumlah luas petakan pada 3 garis transek $=3 *(2 \mathrm{x}$ $\left.10 \mathrm{~m}^{2}\right)=60 \mathrm{~m}^{2}$

Dalam kondisi potensi produksi stok tahunan seimbang antara mortalitas karena tangkapan
(F) dan mortalitas alami (M), yang selanjutnya disebut mortalitas total (Z), maka kondisi eksploitasi dapat dikatakan berkelanjutan (Schuhbauer, et al., 2010). Selanjutnya dikatakan, untuk mencapai hasil maksimum yang lestari (MSY) dari sumber daya yang sudah dipanen, maka rumus yang digunakan adalah (Cadima dalamTroadec, 1977):

$$
\mathrm{MSY}=0,5 * \mathrm{Z} * \mathrm{~B}
$$

Keterangan:

$$
\begin{array}{ll}
\mathrm{D} & =\text { densitas per } \mathrm{m}^{2} \text { saat ini } \\
\mathrm{Z} & =\text { total mortalitas }
\end{array}
$$


Rumus tersebut tidak dapat diterapkan apabila F > M. Rumus dapat diterapkan, apabila $\mathrm{F}=\mathrm{M}$ atau pada saat tingkat eksploitasi $50 \%$, maka $\mathrm{E}=\mathrm{F} / \mathrm{Z}=0,5$, dimana pada stok setelah dilakukan penangkapan, seperti yang ditunjukkan oleh Garcia and LeReste (1981) dalam Schuhbauer, et al., (2010).

Selanjutnya dengan estimasi luasan area studi sampai pada kedalaman $10 \mathrm{~m}$, maka potensi biomasa sumberdaya teripang total per luasan dapat diketahui. Biomasa (B) dapat dicari dari jumlah hasil perkalian antara densitas individu dan luasan area studi, sehingga MSY dapat diketahui dengan rumus : MSY $=0,5^{*} \mathrm{~B}$, dan kuota pengambilan teripang dapat diketahui dari rumus : $0,8^{*}$ MSY. Persamaan ini diusulkan untuk data hasil tangkapan yang terbatas.

\section{Hasil dan Pembahasan Komposisi Spesies}

Hasil transek diperoleh data spesies teripang yang diketemukan di perairan Karimunjawa.Hasil analisismenunjukkan bahwa selama penelitian didapatkan 15 spesies, yang tergolong dalam ordo Aspidochirotidae, meliputi famili Holothuroiidae (11 spesies) dan Stichopodidae. (4 spesies). Kategori nilai komersial spesies teripang yang diketemukan, terdiri dari 5 spesies kategori rendah, 6 kategori medium, 2 kategori tinggi, serta 2 spesies yang tidak dimanfaatkan/tidak laku dijual. Kategori komersial rendah, meliputi $H$. edulis, $P$. graffei, $B$. argus, $B$. similis, dan Bohadschia sp kemudian kategori medium, meliputi Actinopyga sp, A. lecanora,S. vastus, $S$. quadrifasciatus, Stichopus sp-1, dan Stichopus sp2, sedangkan kategori komersial tinggi 2 spesies, meliputi $H$. scabradan $H$. nobilis., serta 2 spesies $H$. atra dan $H$. fuscocinerea merupakan spesies yang tidak laku dijual atau tidak dimanfaatkan oleh masyarakat (Tabel 1).

\section{a. Potensi Pemanfaatan}

Analisis potensi pemanfaatan sumberdaya teripang digunakan data densitas individu per hektar per bulan seluruh spesies yang dimanfaatkan,sedangkan hasil analisis memberikan informasi bahwa densitas individu $\left(\mathrm{ha}^{-1}\right)$ semua spesies yang dimanfaatkan sebesar 19.499 individu $\left(\mathrm{ha}^{-1}\right)$.
Potensi biomasa jumlah individu teripang diestimasi dari data densitas individu $\left(\mathrm{ha}^{-1}\right)$ (Lampiran 1 ) dan data luasan area studi (Tabel 2 di bawah ini). Analisis luasan area sudi dilakukan penghitungan atas dasar area studi sampai pada kedalaman $10 \mathrm{~m}$, dengan menggunakanpeta bathimetri kedalaman perairan Karimunjawa 1(Sumber : Peta Deshidros, TNIAngkatan Laut, 2002), sehingga dapat diketahui luasan area sebesar 1.513,34 ha (Tabel 2).

Setelah diketahui luasan area studi, selanjutnya biomasa seluruh spesies teripang yang ada dalam area studi dapat diestimasi biomasa dari seluruh spesies yang tersebar pada luasan area studi per tahun, diasumsikan selama 1 tahun penangkapan teripang efektif, yakni dihitung selama 9 bulan tangkapan efektif, sehingga berdasarkan densitas individu per hektar per bulan dapat diperoleh jumlah individu per hektar per tahun tangkapan. Hasil analisis menunjukkan bahwa potensi biomasa total spesies teripang di perairan Karimunjawa sebesar 44.641 .789 individu.Nilai potensi biomasa tertinggi terdapat pada $H$. edulis sebesar 11.350 .004 individu dan terendah $H$. scabra sebesar 756.594individu, Actinopyga sp sebesar756.458 individu, dan A. lecanora sebesar 1.134.823 individu (Lampiran 2). Oleh karena itu, jumlah tangkapan sumberdaya teripang di perairan Karimunjawa disarankan tidak boleh melebihi dari nilai potensi lestari (MSY) seluruh spesies sebesar 24.590.814 individu $\left(\operatorname{tahun}^{-1}\right)$, dengan Kuota pengambilan semua spesies yang dimanfaatkan sebesar 20.277.981 individu $\left(\operatorname{tahun}^{-1}\right)$. Untuk spesies kategori komersial tinggi $H$. scabra, pengambilannya tidak boleh melebihi nilai MSY sebesar 378.297individu (tahun ${ }^{-1}$ ) dengan kuota pengambilan per tahun diusulkan sebesar 302.637 individu, untuk kategori komersial medium Actinopyga sp, diusulkan tidak boleh melebihi nilai MSY sebesar 378.229 individu dan dengan kuota pengambilan sebesar 302.583 individu $\left(\operatorname{tahun}^{-1}\right)$, dan kategori komersial medium spesies A. lecanora tidak boleh melebihi nilai potensi lestari sebesar 567.411 individu $\left(\operatorname{tahun}^{-1}\right)$ dengan kuota pengambilan sebesar 453.929 individu $\left(\operatorname{tahun}^{-1}\right)$. 
Tabel 1. Jenis-jenis teripang yang diketemukan di perairan Karimunjawa selama penelitian.

\begin{tabular}{|c|c|c|}
\hline No. & Spesies & $\begin{array}{c}\text { Nilai komersial } \\
\text { (CITES, 2004 \& 2006) }\end{array}$ \\
\hline & H. atra, Lesson, 1833 & Kurang laku dijual \\
\hline 2. & H. edulis, Lesson, 1833 & Rendah \\
\hline 3. & H. fuscocineria, Jaeger, 1883 & Tidak dimanfaatkan \\
\hline 4. & H.. nobilis, Selenka 1816 & Tinggi**) \\
\hline 5. & H. scabra, Jaeger, 1833 & Tinggi \\
\hline 6. & A. lecanora, Jaeger, 1833 & Medium \\
\hline 7. & Actinopyga $\mathrm{Sp}$ & Medium \\
\hline & B. argus Jaeger, 1833 & Rendah \\
\hline 9. & Bohadschia sp & Rendah \\
\hline 10. & B. similis Semper, 1868 & Rendah \\
\hline 11. & P. graffei, Semper, 1868. & Rendah \\
\hline 12. & S. vastus, Sluiter, 1887 & Medium \\
\hline 13. & S. quadrifasciatus, Massin, 1999 & Medium*) \\
\hline 14. & Stichopus Sp-1 & Medium*) \\
\hline 15. & Stichopus Sp -2 & Medium*) \\
\hline
\end{tabular}

Tabel 2. Estimasi Luasan Area Studi

\begin{tabular}{cccc}
\hline $\begin{array}{c}\text { Sintasan } \\
(\mathbf{m})\end{array}$ & $\begin{array}{c}\text { Shape_Lengt } \\
(\mathbf{m})\end{array}$ & $\begin{array}{c}\text { Shape_Area } \\
\left(\text { meter }^{2}\right)\end{array}$ & Luas_ha \\
\hline 1,00 & 4028,581 & $201.332,279$ & 20,133 \\
2,00 & $10.890,312$ & 493.893 .620 & 49,389 \\
3,00 & $19.045,970$ & $700.821,192$ & 70,082 \\
4,00 & $27.580,955$ & $100.6354,182$ & 100,635 \\
5,00 & $31.177,071$ & $1.219 .775,737$ & 121,978 \\
6,00 & $34.431,800$ & $1.375 .353,836$ & 137,535 \\
7,00 & $39.138,777$ & $1.726 .691,261$ & 172,669 \\
8,00 & $48.255,948$ & $3.751 .649,667$ & 375,165 \\
9,00 & $54.053,998$ & $2.596 .939,213$ & 259,694 \\
10,00 & $53.014,253$ & $2.060 .602,454$ & 206,060 \\
\hline Total luasan & $321.617,669$ & $1.513 .3413,446$ & $1.513,340$ \\
\hline \multicolumn{4}{c}{ Sumber : Peta Deshidros, TNI-AL, (2002). }
\end{tabular}

Tabel 3. Jumlah spesies yang ada di beberapa wilayah Perairan Karimunjawa.

\begin{tabular}{llcl}
\hline No. & \multicolumn{1}{c}{ Lokasi } & Jml spesies & \multicolumn{1}{c}{ Referensi } \\
\hline & Di Indonesia & 24 & Aziz (1997) \\
1. & P, Krakal & 5 & Hartati, et al. (1998) \\
2. & P. Karimunjawa, P. Parang, \& & 10 & Azis \& Darsono (1999) \\
& pulau-pulau kecil lainnya, & & \\
3. & P, Karimunjawa & 15 & Sunyoto dalam BTNK (2008) \\
4. & Perairan Karimunjawa & 15 & Dalam penelitian ini \\
\hline
\end{tabular}




\section{Pembahasan}

Teripang merupakan organisme laut yang penting bagi masyarakat Karimunjawa, dengan tingkat pengusahaan yang bersifat subsisten, tradisional, dan berlangsung relatif lama. Namun demikian, belum banyak informasi tentang bagaimana kondisi biologi populasi teripang yang ada saat ini, khususnya pada spesies target tangkapan. Hal ini penting untuk diketahui sebagai bahan masukan dalam pengendalian populasi teripang di perairan Karimunjawa. Selama penelitian, di perairan Karimunjawa telah diketemukan sebanyak 15 spesies yang semuanya termasuk dalam ordo Aspidochirotidae. Hal ini sesuai dengan pendapat Bakus (1973), bahwa ordo Aspidochirotidae merupakan kelompok teripang khas yang mewakili daerah tropis (termasuk di perairan Karimunjawa). Hasil penelitian juga diketahui bahwa dari ordo Aspidochirotidae tersebut, berasal dari 2 famili, yaitu famili Holothuridae dan Stichopodidae. Spesies dari kedua famili tersebut merupakan spesies yang banyak diperdagangkan dan mempunyai nilai komersial penting. Hal ini sesuai dengan pendapat Aziz (1997), di perairan Indonesia terdapat 24 jenis teripang komersial, yang merupakan teripang dari kelasHolothuridea, famili Holothuriidae dan Stichopodidae. Beberapa penelitian yang dilakukan sebelumnya di perairan kawasan Karimunjawa, di antaranya Hartati et al (1990) menemukan 5 spesies di P. Krakal, kemudian Azis dan Darsono (1999), menemukan 10 spesies di P. Geleang, P. Bengkoang, dan P. Kembar, sedangkan Sanyoto dalam BTNK (2008) menemukan 15 spesies di P. Parang, P. Karimunjawa, dan pulau-pulau kecil lainnya (Tabel 3). Beragamnya jumlah spesies ini diduga karena sifat mengelompok speises teripang dan setiap spesies mempunyai kesukaan yang berbeda terhadap jenis habitatnya. Sebagai pembanding kondisi di perairan Pulau Seribu,ditemukan 15 spesies teripang, di antaranya 2 spesies bernilai ekonomis medium (Stichopus variegatus dan Stichopus horrens) dan 9 jenis lainnya mempunyai nilai ekonomi rendah, sedangkan 4 spesies lainnya belum diusahakan (Balai Riset Kelautan dan Perikanan, 2002).

Hasil pengamatan di lapangan, di perairan Karimunjawa, keberadaan spesies $H$. scabra, Actinopyga sp dan A. lecanora sudah mulai langka dan susah didapatkan oleh nelayan, khususnya $H$. scabra. Uthicke dan Conand (2005) dalam CITES (2006), menyatakan bahwa jenis teripang komersial tinggi $H$. scabra di Indonesia dalam status over-eksploitasi, sehingga keberadaannya sudah jarang dketemukan. Dengan demikian diperlukan pengelolaan dan pengawasan yang lebih ketat terhadap spesies tersebut, melalui pengendalian eksploitasi terhadap spesies tersebut. Hal ini dilakukan agar dimasa mendatang spesies teripang komersial tinggi yang selama ini merupakan target tangkapan nelayan setempat tidak mengalami kepunahan.

Hasil analisis potensi pemanfaatan diperoleh informasi bahwa potensi biomasa jumlah individu seluruh spesies yang diketemukan kecuali pada spesies yang tidak dimanfaatkan $(H$. atra dan $H$. fuscocinerea), didapatkan sebesar 44.641.789 individu per hektar. Selanjutnya nilai potensi dari setiap spesies dapat digunakan untuk mengestimasi nilai potensi lestari (maximum Sustainable Yield), Nilai yang diperoleh dapat digunakan catatan bahwa potensi tangkapan dan mortalitas alami dalam kondisi yang seimbang (Schuhbauer, et al, 2010), dengan demikian nilai ini merupakan estimasi 0,5 dari nilai potensinya. Nilai potensi kondisi dalam lestari (MSY) diperoleh dari semua spesies yang diketemukan (kecuali spesies yang tidak dimanfaatkan), sebesar 24.590.814 individu per tahun.

Oleh karena itu jumlah tangkapan yang diperbolehkan dieksploitasi sebaiknya tidak melebihi angka 20.277.981 individu per tahun. Khusus untuk 3 spesies mempunyai potensi biomasa jumlah individu yang relatif rendah, yaitu 756.594 individu per tahun untuk H. scabra, 756.458 individu per tahun untuk Actinopyga sp, dan 1.134.823 individu per tahun untuk $A$. lecanora, sehingga dinilai rawan terhadap kemungkinan punahnya sumberdaya spesies tersebut, dan perlu perhatian khusus, yaitu untuk pengambilan spesies $H$. scabra tidak boleh melebihi potensi lestari sebesar 567.411 individu per tahun dan kuota pengambilannya maksimal sebesar 302.637 individu per tahun, untuk $A$. lecanora tidak melebihi nilai potensi lestari sebesar 567.411 indiividu per tahun, dengan kuota tangkapan yang diperbolehkan sebesar 453.929 individu per tahun, serta untuk Actinopyga sp tidak melebihi nilai potensi lestari sebesar 378.229 individu per tahun, dengan kuota tangkapan maksimal sebesar 302.583 individu per tahun. Nilai potensi lestari (MSY) dan kuota tangkapan yang diperbolehkan untuk 3 spesies yang rawan penurunan populasi dapat dilihat pada Lampiran 2. Atas dasar uraian tersebut, untuk meningkatkan populasi diperlukan regulasi 
tentang jumlah tangkapan teripang yang diperbolehkan sesuai dengan ketentuan yang telah diuraikan tersebut, Khusus untuk 3 spesies target tangkapan, yaitu $H$. scabra, A. lecanora, dan Actinopyga sp yang rawan terhadap penurunan populasi diperlukan perhatian khusus untuk setiap kegiatan eksploitasi yang dilakukan.

\section{Simpulan}

Berdasarkan hasil penelitian dan analisis data yang telah dilakukan, maka dapat diambil kesimpulan sebagai berikut:

a. Selama penelitian telah diketemukan 15 spesies, yang berasal dari ordo Aspidochirotidae dan dari 2 famili, yakni Holothuridae (11 spesies) dan Stichopodidae (4 spesies). Jumlah spesies berdasarkan nilai komersialnya, diketemukan 5 spesies tergolong komersial rendah, 6 spesies komersial medium, dan 2 spesies komersial tinggi, serta 2 spesies yang tidak dimanfaatkan/kurang laku dijual, yaitu $H$. atra dan $H$. fuscocinenera.

b. Potensi biomassa populasi seluruh spesies yang dimanfaatkan dalam area studi sampai pada kedalaman $10 \mathrm{~m}$, diketahui sebesar 44.641 .789 individu dengan nilai potensi leatari (MSY) sebesar 24.590.814 individu per tahun, dengan kuota pengambilan yang diperbolehkan sebesar 20.277.981 individu per tahun. Potensi biomassa populasi spesies yang paling rendah adalah $H$. scabra, Actinopyga sp, dan $A$. lecanora masing-masing sebesar 756.594individu, 756.458 individu, dan 1.134.823 individu, dengan nilai potensi lestari (MSY) masing - masing untuk $H$. scabra sebesar 378.297 individu per tahun, Actinopyga sp sebesar 567.411 individu per tahun dan A. lecanora sebesar 378.229 individu per tahun, serta dengan kuota pengambilan masing-masing sebesar 302.637individu per tahun, 302.583 individu per tahun, dan 302.583 individu per tahun.

\section{Saran}

Untuk dapat meningkatkan populasi Sumberdaya teripang (Holothurian) di perairan Karimunjawa secara lestari, maka strategi yang dilakukan adalah dengan mengembangkan sifat altruistik positip (responsible optimistic), yaitu dengan menyeimbangkan antara aspek eksploitasi dan aspek konservasi secara moderat, antara lain mengoptimumkan eksploitasi sumberdaya teripang sesuai dengan daya dukung dan daya lenting, serta memberikan input kemampuan pada rekrutmen dan laju pertumbuhan melalui pengendalian laju eksploitasi sumberdaya teripang di perairan Karimunjawa.

\section{Ucapan Terima Kasih}

Ucapan terima kasih saya tujuan kepada Prof. Dr. Ir. S. Budi Prayitno, M.Sc dan Drs Ign. Boedi Hendrarto, M.Sc, Ph.D. atas bimbingan dan petunjuk-petunjuknya dalam menyelesaikan penelitian ini.

\section{Daftar Pustaka}

Aziz, Aznam dan Prapto Darsono, 1999. Fauna Echinodermata dari Pulau-pulau Karimunjawa. Majalah Ilmiah Pengembangan ilmu-ilmu Kelautan, Universitas Diponegoro, Nomor 14 tahun IV - Juni 1999 ISSN 0853 - 7291.

Aziz, Aznam, 2008. Beberapa Catatan Tentang Perikutanan Teripang di Indonesia dan Kawasan Indo pasifik Barat. Pusat Penelitisn Oseanografi, Lembaga Ilmu Pengetahuan Indonesia (LIPI). Jakarta dalam http:///.oseanografi.lipi.go.id.

Aziz, A., 1997. Status Penelitian Teripang di Indonesia. Oseana Vol XXII, Nomor 1, 1997 : 9-19.

Balai Riset Perikanan Laut, 2002. Penelitian Biologi, Perikanan dan Habitat Teripang Di Kepulauan Seribu. Laporan riset Tahun Anggaran 2002.

Bengen, Dietrich. G.,2000. Teknik Pengambilan Contoh dan Analisis Data Biofisik Sumberdaya Pesisir. Pusat Kajian Sumberdaya Pesisir dan Lautan, Fakultas Perikanan dan Ilmu Kelautan. Institut Pertanian Bogor. Bogor.

BTNK. 2008. Laporan Pelaksanaan Kegiatan Pembinaan Habitat TeripangTaman Nasional Karimunjawa, Tahun 2008. Semarang.

CITES, 2006.Sea Cucumber. Convention on International Trade In Endangeres Spesies of Wild Fauna and Flora.Twenty-second meeting of the Animals Committee Lima (Peru), 7-13 July 2006.

Darsono, P. 2006. Upaya Budidaya Teripang (Holothuridea, Echinodermata) : Pembenihan Teripang Pasir Holothuria scabra (Jaeger). Orasi Pengukuhan Profesor 
Riset Bidang Sumberdaya Laut. Lembaga Ilmu Pengetahuan Indonesia, Jakarta, Desember 2006.

Hartati et al 1990. Kelimpahan Teripang (Holothuroidea) di pulau Krakal Kecil, Kepulauan Karimunjawa. Jurusan Ilmu Kelautan, FPIK - UNDIP, Semarang.

Misra, R., 1968.Ecological Workbook.Oxford and IBM Pub.Co New Delhi.

Manuputty dan Djuwariah, 2009.Panduan Metoda Point Intercept Transeck (PIT) untuk Masyarakat.Coral Reef Rehabilitation and Management Program.Lembaga Ilmu
Pengetahuan Indonesia. COREMAP II LIPI, Jakarta 2009.

Sandjaya. 2006. Metode Penelitian Ilmiah. PT. Gramedia. Jakarta.

Schuhbauer, A., Matthias Wolff, and Mauricio Castrejon. 2010. A Revised strategy for the monitoring and management of the Galapagos sea cucumber. Charles Darwin Foundation - WWF.Galapagos report 2009-2010.Shiell 2003

Troadec, J. P., 1977. Methodes SemiQuantitatives d'evaluation. FAO Circ. Peches 701, pp. 131-141. 
Lampiran 1. Densitas Individu $\left(\mathrm{ha}^{-1}\right)$ Spesies Teripang yang Dimanfaatkan Setiap Stasiun Penelitian

\begin{tabular}{|c|c|c|c|c|c|c|}
\hline Spesies & Sta. A & Sta. B & Sta. C & Sta. D & Sta. E & Jml slruh stasiun \\
\hline \multicolumn{7}{|l|}{ Holothuriidae } \\
\hline H. edulis & 166,66 & 333,33 & $1.333,33$ & $2.000,00$ & $1.166,66$ & 4999,98 \\
\hline H.nobilis & 0 & 0 & 166,66 & 0 & 500,00 & 666.66 \\
\hline H. scabra & 333,33 & 0 & 0 & 0 & 0 & 333,33 \\
\hline A. lecanora & 333,33 & 166,66 & 0 & 0 & 0 & 499,99 \\
\hline Actinopyga sp & 0 & 166,66 & 0 & 0 & 166,66 & 333,32 \\
\hline Bohadschia sp & 500,00 & 0 & 166,66 & 0 & 0 & 666,66 \\
\hline B. argus & 0 & 666,66 & 333,33 & 0 & 0 & 999,99 \\
\hline B.similis & 333,33 & 0 & 166,66 & 0 & $1.666,66$ & $2.166,65$ \\
\hline P. graffei & 666,66 & 0 & 333.33 & 0 & 0 & 999.99 \\
\hline \multicolumn{7}{|l|}{ Stichopodidae } \\
\hline S. vastus & $1.500,00$ & 666,66 & 166,66 & 166,66 & $1.166,66$ & $3.666,64$ \\
\hline $\begin{array}{l}\text { S. } \\
\text { quadrifasciatus }\end{array}$ & 0 & 166,66 & $1.166,66$ & 500,00 & 0 & $1.833,32$ \\
\hline Stichopus sp-1 & 0 & 166,66 & 0 & 0 & $1.666,66$ & $1.833,32$ \\
\hline Stichopus sp-2 & 0 & 333,33 & 0 & 0 & 166,66 & 499,99 \\
\hline Jumlah & $3.883,31$ & $2.666,62$ & $3.822,29$ & $2.666,66$ & $6.499,96$ & $19.499,84$ \\
\hline
\end{tabular}

Ket : Sta A = Menjangan Kecil

Sta B = Legon Goprak

Sta $\mathrm{C}=$ Karang gumuk

Sta D = Alang-alang

Sta $\mathrm{E}=$ Mrican

Lampiran 2. Hasil Analisis Potensi Pemanfaatan Sumberdaya Teripang berdasarkan Jumlah Individu Per Spesies Selama Penelitian.

\begin{tabular}{|c|c|c|c|c|c|c|c|}
\hline No. & Spesies & $\begin{array}{l}\sum_{\text {indiv./ha. }} \\
\text { rerata } \\
\text { per bln }\end{array}$ & $\begin{array}{c}\text { Individu/ha/th } \\
\text { (rerata per } \\
\text { bulan } x 9 \\
\text { bulan efektif) }\end{array}$ & $\begin{array}{l}\text { Luas } \\
\text { Area }\end{array}$ & $\begin{array}{c}\text { PotensiBiomasa } \\
\text { individu } \\
(\text { per tahun }\end{array}$ & $\begin{array}{c}\text { MSY } \\
(\mathbf{0 , 5} \\
\text { *Biomassa })\end{array}$ & $\begin{array}{c}\text { Kuota } \\
(0,8 * \text { MSY })\end{array}$ \\
\hline 1. & H. edulis & 833,31 & $7.499,97$ & $1.513,34$ & $11.350 .004,6$ & $5.675 .002,30$ & $4.540 .001,84$ \\
\hline 2. & H.nobilis & 111,11 & 999,99 & $1.513,34$ & $1.513 .324,86$ & $756.662,43$ & $605.329,94$ \\
\hline 3. & H. scabra & 55,55 & 499,95 & $1.513,34$ & $756.594,33$ & $378.297,16$ & $302.637,73$ \\
\hline 4. & A. lecanora & 83,32 & 749,88 & $1.513,34$ & $1.134 .823,39$ & $567.411,69$ & $453.929,36$ \\
\hline 5. & Actinopyga sp & 55,54 & 499,86 & $1.513,34$ & $756.458,13$ & $378.229,66$ & $302.583,25$ \\
\hline 6. & Bohadschia sp & 111,11 & 999,99 & $1.513,34$ & $1.513 .324,86$ & $756.662,43$ & $605.329,94$ \\
\hline 7. & B. argus & 166,66 & $1.499,94$ & $1.513,34$ & $2.269 .919,2$ & $1.134 .959,60$ & $907.967,68$ \\
\hline 8. & B.similis & 361,09 & $3.249,81$ & $1.513,34$ & $4.918 .067,46$ & $2.459 .033,73$ & $1.967 .226,98$ \\
\hline 9. & P. graffei & 166,66 & 1499,94 & $1.513,34$ & $2.269 .919,2$ & $4.161 .541,23$ & $3.329 .232,98$ \\
\hline 10. & S. vastus & 611,09 & $5.499,81$ & $1.513,34$ & $8.323 .082,46$ & $4.161 .541,23$ & $3.329 .232,98$ \\
\hline 11. & S. quadrifasciatus & 305,54 & $2.749,86$ & $1.513,34$ & $4.161 .473,13$ & $2.080 .736,56$ & $1.664 .589,25$ \\
\hline 12. & Stichopus sp-1 & 305,54 & $2.749,86$ & $1.513,34$ & $4.161 .473,13$ & $2.080 .736,56$ & $1.664 .589,25$ \\
\hline 13. & Stichopus sp -2 & 111,11 & 999,99 & $1.513,34$ & $1.513 .324,86$ & $756.662,43$ & $605.329,94$ \\
\hline \multicolumn{5}{|c|}{ Jumlah } & $44.641 .789,61$ & $24.590 .814,58$ & $20.277 .981,12$ \\
\hline
\end{tabular}

